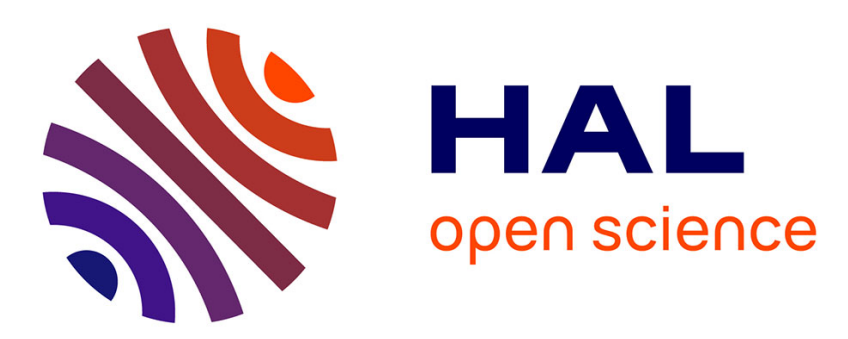

\title{
A 3D reconstruction method of the body envelope from biplanar X-rays: Evaluation of its accuracy and reliability
}

Agathe Nérot, Julie Choisne, Célia Amabile, Christophe Travert, Hélène

Pillet, Xuguang Wang, Wafa Skalli

\section{To cite this version:}

Agathe Nérot, Julie Choisne, Célia Amabile, Christophe Travert, Hélène Pillet, et al.. A 3D reconstruction method of the body envelope from biplanar X-rays: Evaluation of its accuracy and reliability. Journal of Biomechanics, 2015, 48 (16), pp.4322-4326. 10.1016/j.jbiomech.2015.10.044 . hal-02474289

\section{HAL Id: hal-02474289 \\ https://hal.science/hal-02474289}

Submitted on 11 Feb 2020

HAL is a multi-disciplinary open access archive for the deposit and dissemination of scientific research documents, whether they are published or not. The documents may come from teaching and research institutions in France or abroad, or from public or private research centers.
L'archive ouverte pluridisciplinaire HAL, est destinée au dépôt et à la diffusion de documents scientifiques de niveau recherche, publiés ou non, émanant des établissements d'enseignement et de recherche français ou étrangers, des laboratoires publics ou privés. 


\title{
A 3D reconstruction method of the body envelope from biplanar $\mathrm{X}$-rays: Evaluation of its accuracy and reliability
}

\author{
Agathe Nérot ${ }^{\mathrm{a}, \mathrm{b}, \mathrm{c}, \mathrm{d}, *}$, Julie Choisne ${ }^{\mathrm{a}}$, Célia Amabile ${ }^{\mathrm{a}, \mathrm{e}}$, Christophe Travert ${ }^{\mathrm{a}}$, Hélène Pillet ${ }^{\mathrm{a}}$, \\ Xuguang Wang ${ }^{\mathrm{b}, \mathrm{d}, \mathrm{d}}$, Wafa Skalli ${ }^{\mathrm{a}}$ \\ ${ }^{a}$ Arts et Métiers ParisTech., LBM/Institut de Biomécanique Humaine Georges Charpak, 151, Boulevard de l'hôpital, 75013 Paris, France \\ ${ }^{\mathrm{b}}$ Université de Lyon, F-69622 Lyon, France \\ ${ }^{c}$ Université Claude Bernard Lyon 1, Villeurbanne, France \\ d IFSTTAR, UMR_T9406, LBMC Laboratoire de Biomécanique et Mécanique des Chocs, F69675, Bron, France \\ e Department of Orthopaedic Surgery, NYU Hospital for Joint Diseases, New York, NY, USA
}

Keywords:

Body envelope

Geometric modeling

Biplanar X-rays

Reproductibility

Joint center

\begin{abstract}
A B S T R A C T
The aim of this study was to propose a novel method for reconstructing the external body envelope from the low dose biplanar X-rays of a person. The 3D body envelope was obtained by deforming a template to match the surface profiles in two X-rays images in three successive steps: global morphing to adopt the position of a person and scale the template's body segments, followed by a gross deformation and a fine deformation using two sets of pre-defined control points. To evaluate the method, a biplanar X-ray acquisition was obtained from head to foot for 12 volunteers in a standing posture. Up to 172 radioopaque skin markers were attached to the body surface and used as reference positions. Each envelope was reconstructed three times by three operators. Results showed a bias lower than $7 \mathrm{~mm}$ and a confidence interval (95\%) of reproducibility lower than $6 \mathrm{~mm}$ for all body parts, comparable to other existing methods matching a template onto stereographic photographs. The proposed method offers the possibility of reconstructing body shape in addition to the skeleton using a low dose biplanar X-rays system.
\end{abstract}

\section{Introduction}

3D body scanning technologies are becoming accessible making it possible to easily obtain 3D body shape (Daanen and Haar, 2013; Liu et al., 2015). For instance, Park et al. (2015) recently reported that full child shape could be measured with a good accuracy using low-cost depth cameras and a statistical body shape model. To create personalized human model with an articulated linkage for re-posturing or movement analysis, an accurate estimation of internal joint centers is required. Anatomical landmarks (ALs) generally need to be manually identified on the body mesh so as to estimate joint centers. Not only the palpation of ALs requires specific training, but this is also a very time consuming process. Recently, methods were proposed to automatically locate ALs on body shape scans by non-rigid model fitting (Yamazaki et al., 2013) or using a statistical shape model (Reed et al., 2015). But relationships between ALs and joint centers are missing in general due to lack of in vivo data from human

\footnotetext{
* Correspondence to: IFSTTAR, UMR_T9406, LBMC Laboratoire de Biomécanique et Mécanique des Chocs, 25 avenue François Mitterrand, Case24 Cité des mobilités, F69675, Bron, France.

E-mail address: agathe.nerot@ifsttar.fr (A. Nérot).
}

beings (Reed et al., 1999). Therefore there is a need to collect data which contains both external body surface and internal skeleton geometries.

Recent development of low dose bi-planar X-rays (BPXr) (Dubousset et al., 2010) allows the 3D reconstruction of subjects' skeleton in an upright posture (Mitton et al., 2006; Humbert et al., 2009; Chaibi et al. 2012; Quijano et al., 2013; Aubert et al., 2014) while the skin contour is also visible on the radiographs. Using this technology, Sandoz et al. (2010) proposed a method for reconstructing the external body envelope. Eleven template meshes representing the 11 different body segments were morphed on skin contour and then combined to obtain an entire reconstruction of the body. However the method was only validated on a few male subjects and the separate reconstruction of different body segments was a time-consuming process requiring a work day per subject. Global morphing of a template mesh of the whole body envelope would allow reduction of the reconstruction time.

The aim of the present study was to propose a new method for reconstructing the $3 \mathrm{D}$ external body envelope from $\mathrm{BPXr}$ as well as a procedure for its validation. A 3D surface mesh template was morphed to match body surface profiles in two orthogonal BPXr. The method was validated by comparing the reconstructed surface 
to the locations of up to 172 radiopaque markers uniformly attached to the body skin surface on 12 participants.

\section{Material and methods}

\subsection{Data collecting}

After approval of the ethical committee (CPP 06036) and written informed consent, 12 volunteers ( 6 males, 6 females, average age: $26.8+3.1$, average BMI: $23.6 \pm 2.9 \mathrm{~kg} / \mathrm{m}^{2}$ ) participated in data collecting. 172 radio-opaque markers (150 of $\varnothing 2 \mathrm{~mm}$ and 22 of $\varnothing 5 \mathrm{~mm}$ ) were uniformly placed on the participants' skin from head to foot excluding the arms, including a hair cap with 10 markers. Participants were asked to adopt a standard position (Steffen et al., 2010). Two calibrated orthogonal BPXr (EOS Imaging, Paris, France) were simultaneously acquired in $18 \mathrm{~s}$ (exposure parameters: $0.5 \mathrm{mGy}$, face radiograph: $90 \mathrm{kV}, 190 \mathrm{~mA}$, profile: $105 \mathrm{kV}$, $250 \mathrm{~mA}$ )

\subsection{Envelope reconstruction method}

The 3D body envelope was obtained by deforming a template to match the surface profiles in two BPXr. The template matching procedure included three successive steps: global morphing to adopt the participant's position and scale the template's body segments, followed by a gross deformation, and a fine deformation to fit the template surface profiles to the X-rays. As the arms exceeded the acquisition area, only an armless mesh was reconstructed.

Two reference templates were created corresponding to an average height male $(1.75 \mathrm{~m}, 70 \mathrm{~kg})$ and female $(1.68 \mathrm{~m}, 60 \mathrm{~kg})$ in the EOS standing position whose BPXr were available from a previous study. A male (12,035 nodes, 24,068 triangles) and female ( 12,243 nodes, 24,484 triangles) artist representation from the MakeHuman $^{\mathrm{TM}}$ Open Source application 1.0.1. (The MakeHuman team, https:// www.makehuman.org) were initially used and manually deformed to match the two reference subjects with help of the Blender software v.2.72b (Blender Foundation, https://www.blender.org). Three sets of control points were pre-defined on the two templates (Fig. 1a) and successively used for the body envelope reconstruction for each participant from his/her BPXr.

The first set of control points contained the location of the crotch and 10 joint centers in order to scale the body envelope template onto the participants' radiographs. The corresponding points of a target participant had to be manually identified on the radiographs by an operator (Fig. 1b). Then, they were used to globally morph the template to the position of the participant by a moving least square algorithm (MLS) (Cuno et al., 2007) providing an "as-rigid-as-possible" deformation of the template model (called 'global morphing'). The deformed template was automatically projected on the two radiographs (Fig. 1c) together with all control points.

The second set included 49 skin points, used to locally deform the envelope by using MLS in the second step (called 'first deformation'). They were disposed on the body parts of high shape variation between individuals such as the back of the calf and the waist which depend on subjects' weight and muscle structures. By manually moving each of these skin control points, the template could be deformed to grossly match the contour from the front and profile radiographs. A precustomized surface model called "initial solution" could thus be achieved (Fig. 1d).

Finally an additional set of 71 points were proposed for a fine deformation of the template (called 'fine deformation'). They were once again located depending on human shape variations which need a refinement such as the buttocks curvature and the abdomen bulge. Each of these 71 points could be dragged with help of the mouse to control the local deformation of a body region using a kriging algorithm (Trochu, 1993) (Fig. 1e)

\section{Assessment of the reconstruction method}

\subsubsection{Reference points}

Among 172 radio-opaque spherical markers stuck to the body surface, on average $123(+13)$ markers per participant was automatically detected on the radiographs using a pixel-wise comparison of the image with a reference pattern (i.e. cross-correlation). They were used as reference points to evaluate the accuracy and reproducibility of the reconstructed surface. Accuracy of the markers detection method was assessed with an average error of $0.045 \mathrm{~mm}(2 \mathrm{SD}<0.06 \mathrm{~mm})$. Because of the markers' size, the marker skin contact point was defined as the marker center translated by the marker's radius in the direction normal to the external surface of the reconstructed envelope. As the hair cap with markers worn by the participants was not directly in contact with the skull, an offset of $5 \mathrm{~mm}$ (representing the average distance between skull and hair cap) was used.

\subsubsection{Corrected envelope}

To evaluate the error map, a reference envelope was obtained using the radioopaque markers as new control points by deforming the reconstructed envelope, resulting in a corrected envelope passing through these reference points.

\subsubsection{Bias and reproducibility}

An inter-intra operator variability study was performed to evaluate the error due to manual adjustments of control points. Three operators performed the reconstruction of 12 participants three times. The instruction given to the operators was to match the reference template to the two radiographic profiles as closely as possible. All operators were trained with the help of an experienced person using a sample set of six subjects' radiographs of different anthropometric dimensions which were not used for the method's evaluation.

Bias and reproducibility variance of the method were assessed as recommended by the International Organization for Standardization (ISO 5725-1-2).

- For each reference marker that was successfully detected, the bias was defined as the average signed point-to-surface distance between the reference radioopaque markers and the reconstructed surfaces obtained from all operators.

- For each participant $i$, the reproducibility variance $\left(S_{\mathrm{Ri}}^{2}\right)$ expressed the variability in the mesh nodes distribution of reconstructed envelopes that is due to the variability among operators. It involved the interoperator $\left(S_{\mathrm{Li}}^{2}\right)$ and intraoperator
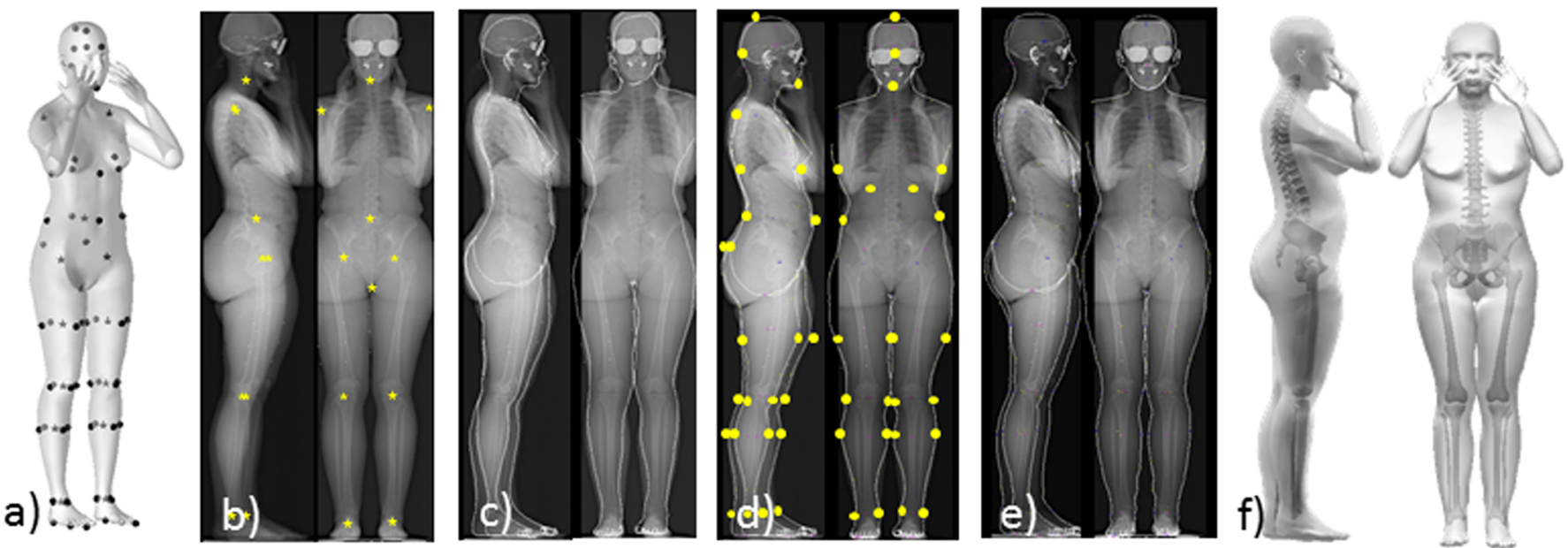

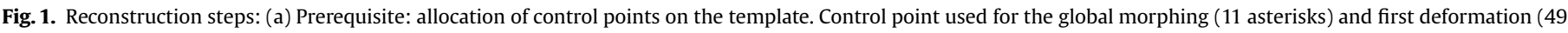

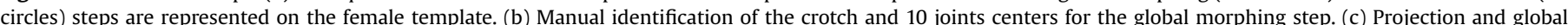

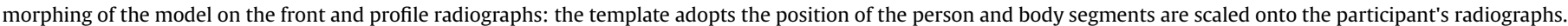

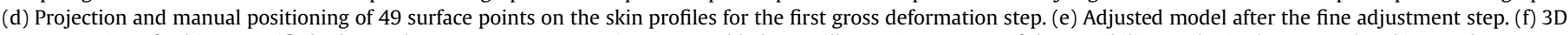

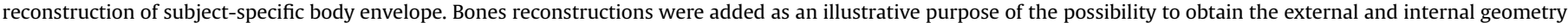
of the body. 
variances $\left(S_{\mathrm{ri}}^{2}\right)$ :

$S_{\mathrm{Ri}}^{2}=S_{\mathrm{Li}}^{2}+S_{\mathrm{ri}}^{2}$

where $S_{\mathrm{ri}}^{2}$ was the mean of the variances of three reconstructions performed by each operator (intraoperator variance); $S_{\mathrm{Li}}^{2}$ quantified the variance of the mean reconstructions obtained between operators (interoperator variance)

Finally the global reproducibility variance $\left(S_{R}\right)$ over the $n$ participants $(n=12)$ was calculated as follow:

$S_{\mathrm{R}}=\sqrt{\frac{\sum_{i=1}^{n} S_{\mathrm{Ri}}{ }^{2}}{n}}$

A confidence interval at the $95 \%$ confidence level $(95 \% \mathrm{CI})$ was considered as $2 * S_{\mathrm{R}}$ as an indicator of the global uncertainty.

\section{Results}

The bias was assessed for each subject using detected markers and was comprised between - 6.7 and $2.3 \mathrm{~mm}$ (Table 1). Mean (respectively max) marker-to-surface absolute distance was 4.9 (9.0) $\mathrm{mm}$. 95\% CI of reproducibility was smaller than $5.8 \mathrm{~mm}$ (Table 1). Higher accuracy errors were distributed along the lateral parts of the thorax and the abdomen compared to the middle area (Fig. 2a). Regarding reproducibility, local maxima did not exceed $20 \mathrm{~mm}$ (Fig. 2b).

\section{Discussion}

A method allowing the reconstruction of the body envelope from BPXr by matching a 3D body shape template was proposed in this study. Reconstruction errors were comparable to other previous studies (Lin and Wang, 2012; Lee, 2000; Zhu et al., 2013), with mean absolute values ranging from 8 to $13 \mathrm{~mm}$. Moreover with BPXr, both the external envelope and internal skeleton of the whole body become accessible from a same set of images (Fig. 1f) while other medical imaging techniques such as MRI (Bauer et al., 2007; Cheng et al., 2000; Mungiole and Martin, 1990) or CT-Scan (Huang and Suarez, 1983; Pearsall et al., 1994) can only generate partial reconstructions due to high cost, long post-processing and/ or exposure to radiation. In addition this method allows straight-forward identification of ALs for joint centers estimation by projecting subcutaneous bony landmarks on the envelope surface. This approach was implemented in a preliminary study (Nérot et al., 2015) for hip joint center (HJC) prediction proposing new predictors from the body surface in addition to commonly used ALs. Parameters such as distances between anatomical landmarks (ALs), barycenter of the body segments or elliptic shape descriptors at the section of the anterior superior iliac spine, were used as predictors. Results were comparable or even better than other existing methods which require the accurate location of some ALs based on manual palpation.

The proposed method allows for template scaling which makes it not sensitive to subject's height and weight. A very different body shape from the template may require more time to get a good fitting. In our test sample of 6 males and 6 females with different height and weight (Table 1), high errors in reconstructed envelopes were not observed for extreme height and weight participants. Work is in progress to evaluate the method for an elderly population whose overall posture and surface contour may be very different from that of the template used in the present study. If necessary, additional templates and/or control points could be added for a better matching with the target subject's contour, requiring more time for the morphing process.

However, it should be mentioned that the EOS bi-planar X-ray system is limited to $34 \mathrm{~cm}$ in width for the radiographic acquisition. The front view of the medial and lateral contours of the torso was frequently missing even for fairly lean participants. Missing contours were approximately interpolated using visible contours yielding higher reconstruction errors. Improvement of the method could consider estimating the missing information based on statistical shape models.

Another limitation is that template matching is operator dependent and still a time consuming process. Even though the reconstruction time was drastically reduced to 20 min compared to the one proposed by Sandoz et al. (2010), matching the control points on the radiographic profiles remained mostly manual Therefore operator training (approximately $5 \mathrm{~h}$ ) is necessary to use the software, especially for better handling of available control points. Work is in progress for automatic contour detection from the images for a less operator dependent process.

As conclusion, the proposed method allows for simultaneously collecting the external envelope and internal skeleton on a broad population. It opens the way to a large exploration for locating joint centers from the characteristics of external body shape in addition to the traditional ALs for a more accurate prediction of internal skeleton location.

Table 1



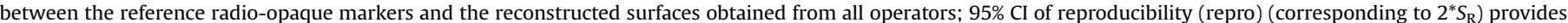
an indicator of the global uncertainty on mesh nodes distribution due to the variability among subjects (in $\mathrm{mm}$ ).

\begin{tabular}{|c|c|c|c|c|c|c|c|c|c|}
\hline & Subject & Height & Weight & Thorax & Abdomen & Head & Thighs & Lower legs & Feet \\
\hline \multirow[t]{8}{*}{ Men } & 1 & 1.88 & 84.4 & $1.7 \pm 9.1$ & $0.9 \pm 7.1$ & $-3.6 \pm 2.3$ & $-1.0 \pm 6.0$ & $-1.7 \pm 3.9$ & $-3.0 \pm 2.6$ \\
\hline & 2 & 1.75 & 69.1 & $-1.8 \pm 8.6$ & $2.3 \pm 11.1$ & $-1.3 \pm 3.2$ & $-1.5 \pm 5.6$ & $-3.4 \pm 4,0$ & $-3.7 \pm 2.9$ \\
\hline & 3 & 1.82 & 76.5 & $1.0 \pm 11.3$ & $0.8 \pm 6.9$ & $-0.8 \pm 3.5$ & $-2.5 \pm 5.6$ & $-2.6 \pm 3.3$ & $-5.3 \pm 3.5$ \\
\hline & 4 & 1.87 & 88.1 & $0.5 \pm 11.8$ & $1.6 \pm 10.3$ & $-1.5 \pm 6.7$ & $-1.5 \pm 6.1$ & $-3.3 \pm 3.6$ & $-3.5 \pm 3.3$ \\
\hline & 5 & 1.87 & 103.3 & $1.5 \pm 10.7$ & $0.1 \pm 8.6$ & $-2.2 \pm 7.1$ & $-3.2 \pm 6.5$ & $-4.8 \pm 3.6$ & $-6.5 \pm 4.5$ \\
\hline & 6 & 1.75 & 63.2 & $1.1 \pm 7.1$ & $-0.8 \pm 6.5$ & $-0.8 \pm 3.5$ & $-2.7 \pm 5.4$ & $-6.7 \pm 3.6$ & $-1.5 \pm 7.7$ \\
\hline & & & Mean bias & 0.70 & 0.8 & -1.7 & -2.1 & -3.8 & -3.9 \\
\hline & & & 95\% CI repro & 5.8 & 4.9 & 4.0 & 2.9 & 3.0 & 3.7 \\
\hline \multirow[t]{8}{*}{ Women } & 7 & 1.74 & 64.3 & $-0.5 \pm 5.7$ & $0.2 \pm 5.8$ & $1.7 \pm 6.4$ & $-1.2 \pm 3.9$ & $-3.2 \pm 2.5$ & $-2.2 \pm 3.9$ \\
\hline & 8 & 1.66 & 55.1 & $0.1 \pm 8.5$ & $-0.6 \pm 4.4$ & $-2.8 \pm 3.8$ & $-1.4 \pm 4.0$ & $-3.2 \pm 2.4$ & $-2.6 \pm 2.8$ \\
\hline & 9 & 1.63 & 60.7 & $-1.9 \pm 8.5$ & $-2.2 \pm 6,0$ & $-1.1 \pm 2.5$ & $-2.4 \pm 4.5$ & $-4.2 \pm 3.2$ & $-1.3 \pm 5.7$ \\
\hline & 10 & 1.62 & 74.5 & $-5.7 \pm 5.6$ & $-3.8 \pm 6.7$ & $-1.9 \pm 2.4$ & $-3.9 \pm 4.3$ & $-3.6 \pm 2.1$ & $-3.9 \pm 2.6$ \\
\hline & 11 & 1.65 & 59.1 & $1.1 \pm 9.9$ & $-1.5 \pm 7.8$ & $-2.4 \pm 3.2$ & $-2.2 \pm 4.6$ & $-4.3 \pm 3.1$ & $-4.0 \pm 3.8$ \\
\hline & 12 & 1.63 & 65 & $-1.5 \pm 7.1$ & $-1.1 \pm 6.1$ & $-2.8 \pm 4.1$ & $-2.9 \pm 4.7$ & $-3.4 \pm 2.3$ & $-3.4 \pm 3.6$ \\
\hline & & & Mean bias & -1.4 & -1.5 & -1.6 & -2.4 & -3.7 & -2.9 \\
\hline & & & 95\% CI repro & 1.2 & 5.9 & 4.1 & 3.7 & 3.5 & 4.6 \\
\hline \multirow[t]{2}{*}{ All } & & & Mean bias & -0.4 & -0.4 & -1.6 & -2.2 & -3.7 & -4.0 \\
\hline & & & 95\% CI repro & 0.9 & 5.4 & 4.0 & 3.30 & 3.3 & 4.1 \\
\hline
\end{tabular}


a

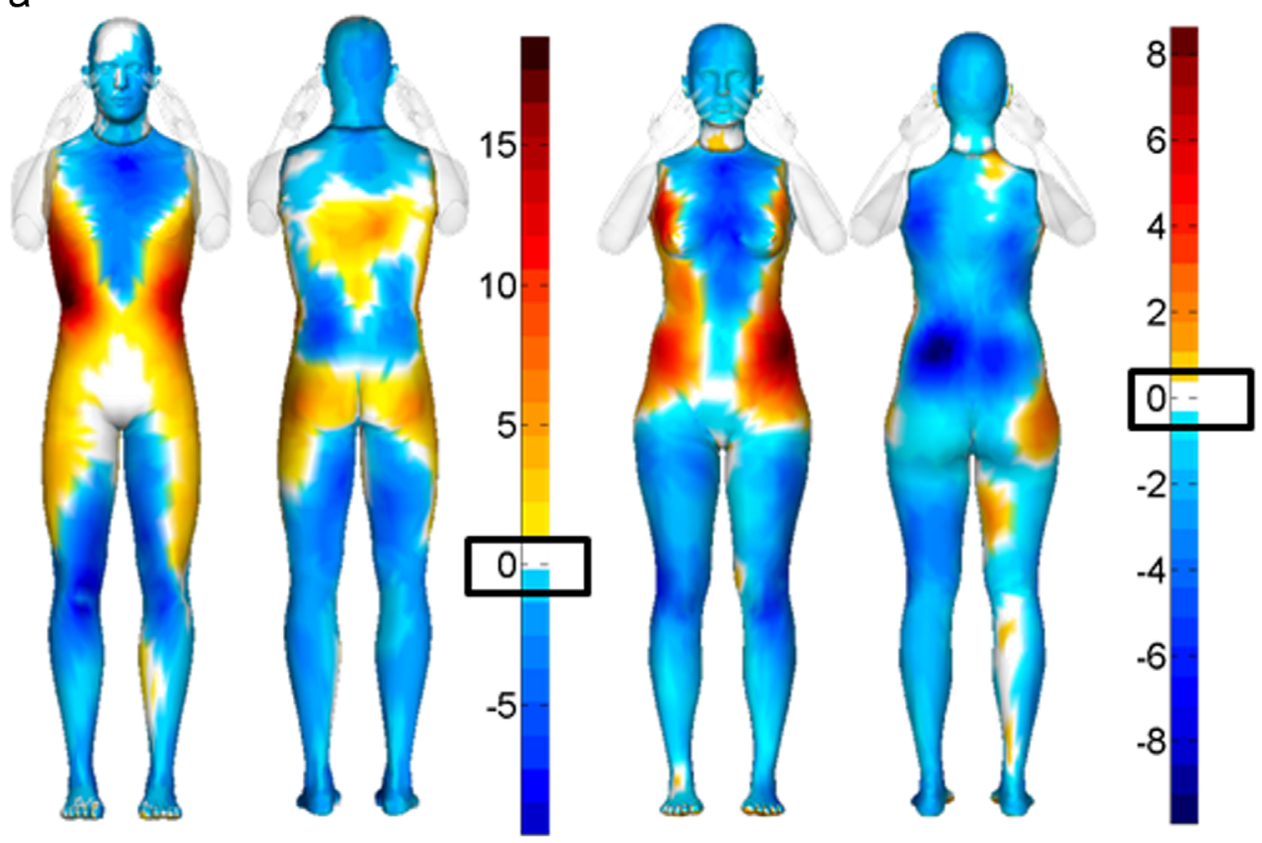

b

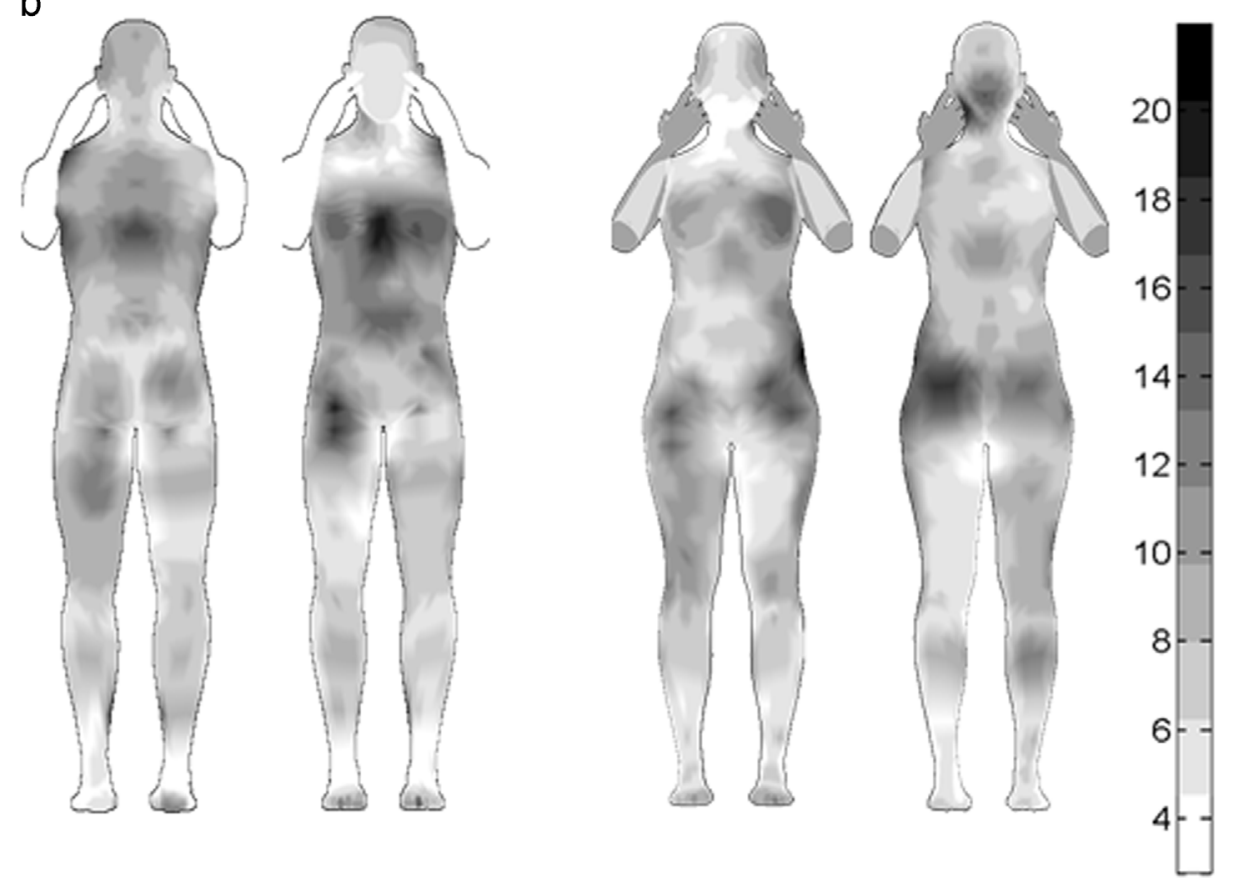

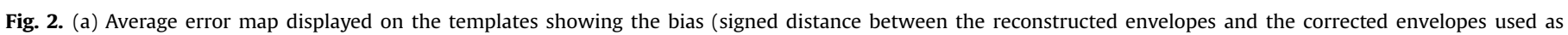
reference) in $\mathrm{mm}$ for male (a) and female (b).

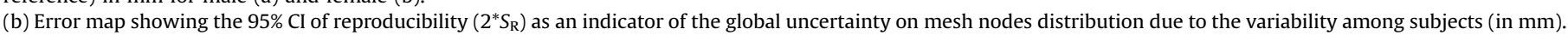
Only an armless mesh was reconstructed. Generic arm meshes were afterwards merged to the reconstructed surface for visual purpose.

\section{Conflict of interest statement}

The authors have no conflicts of interest to declare.

\section{Acknowledgments}

The authors thank the ParisTech BiomecAM chair program on subject-specific musculoskeletal modeling, and in particular COVEA and Société Générale. A part of the evaluation was also performed within the support of the dexEOS project part of the FUI14 program. The authors thank Sonia Simoes, Thomas Joubert and Christophe Gatt for their technical assistance.

\section{References}

Aubert, B., Vergari, C., Ilharreborde, B., Courvoisier, A., Skalli, W., 2014. 3D reconstruction of rib cage geometry from biplanar radiographs using a statistical parametric model approach. Comput. Methods Biomech. Biomed. Eng.: Imaging 
Vis., 1-15. http://dx.doi.org/10.1080/21681163.2014.913990 (Epub ahead of print).

Bauer, J.J., Pavol, M.J., Snow, C.M., Hayes, W.C., 2007. MRI-derived body segment parameters of children differ from age-based estimates derived using photogrammetry. J. Biomech. 40 (13), 2904-2910. http://dx.doi.org/10.1016/j. jbiomech.2007.03.006.

Blender Foundation, www.blender.org, Blender Institute BV, Amsterdam, The Netherlands ( $\langle$ http://www.blender.org/ $\rangle$ ).

Chaibi, Y., Cresson, T., Aubert, B., Hausselle, J., Neyret, P., Hauger, O., de Guise, J.A., Skalli, W., 2012. Fast 3D reconstruction of the lower limb using a parametric model and statistical inferences and clinical measurements calculation from biplanar X-rays. Comput. Methods Biomech. Biomed. Eng. 15 (5), 457-466. http: //dx.doi.org/10.1080/10255842.2010.540758.

Cheng, C.K., Chen, H.H., Chen, C.S., Lee, C.L., Chen, C.Y., 2000. Segment inertial properties of chinese adults determined from magnetic resonance imaging. Clin. Biomech. 15, 559-566. http://dx.doi.org/10.1016/S0268-0033(00)00016-4.

Cuno, A., Esperanc, C., Oliveira, A., Cavalcanti, P.R., 2007. 3D as-rigid-as-possible deformations using MLS. In: Proceedings of the 27th Computer Graphics International Conference, Petropolis, RJ, Brazil, pp. 115-122.

Daanen, H., Haar, F.T., 2013. 3D whole body scanners revisited. Displays 34 (4), $270-275$.

Dubousset, J., Charpak, G., Skalli, W., de Guise, J.A., Kalifa, G., 2010. Eos: a new imaging system with low dose radiation in standing position for spine and bone \& joint disorders. J. Musculoskelet. Res. 13 (01), 1-12. http://dx.doi.org/ 10.1142/S0218957710002430.

Steffen, J.S., Obeid, I., Aurouer, N., Hauger, O., Vital, J.M., Dubousset, J., Skalli, W., 2010. 3D postural balance with regard to gravity line: an evaluation in the transversal plane on 93 patients and 23 asymptomatic volunteers. Eur. Spine J. 19, 760-767. http://dx.doi.org/10.1007/s00586-009-1249-5.

Huang, H.K., Suarez, F.R., 1983. Evaluation of cross-sectional geometry and mass density distributions of humans and laboratory animals using computerized tomography. J. Biomech. 16, 821-832.

Humbert, L., de Guise, J.A., Aubert, B., Godbout, B., Skalli, W., 2009. 3D reconstruction of the spine from biplanar $\mathrm{x}$-rays using parametric models based on transversal and longitudinal inferences. Med. Eng. Phys. 31 (6), 681-687. http: //dx.doi.org/10.1016/j.medengphy.2009.01.003.

Lee, W., 2000. Feature-based Approach on Animatable Virtual Human Cloning (Ph.D thesis). MIRALab, University of Geneva, Switzerland.

Lin, Y.L., Wang, M.J.J., 2012. Constructing 3D models from front and side images. Experts Syst. Appl. 39, 5012-5018.

Liu, Z., Qin, H., Bu, S., Yan, M., Huang, J., Tang, X., Han, J., 2015. 3D real human reconstruction via multiple low-cost depth cameras. Signal Process. Learn. Methods 3D Semant. Anal. 112, 162-179.
Mitton, D., Deschênes, S., Laporte, S., Godbout, B., Bertrand, S., De Guise, J.A., Skalli, W., 2006. 3D reconstruction of the pelvis from bi-planar radiography. Comput. Methods Biomech. Biomed. Eng. 9 (1), 1-5.

Mungiole, M., Martin, P.E., 1990. Estimating segment inertial properties: comparison of magnetic resonance imaging with existing methods. J. Biomech. 23 (10), 1039-1046. http://dx.doi.org/10.1016/0021-9290(90)90319-X.

Nérot, A., Wang, X., Pillet, H., Skalli, W., 2015. Estimation of hip joint center from the external body shape: a preliminary study. Comput. Methods Biomech. Biomed. Eng. 3, 1-2.

Park, B.K., Lumeng, J.C., Lumeng, C.N., Ebert, S.M., Reed, M.P., 2015. Child body shape measurement using depth cameras and a statistical body shape model. Ergonomics 58 (2), 301-309. http://dx.doi.org/10.1080/00140139.2014.965754.

Pearsall, D.J., Reid, J.G., Ross, R., 1994. Inertial properties of the human trunk of males determined from magnetic resonance imaging. Ann. Biomed. Eng. 22 (6), 692-706. http://dx.doi.org/10.1007/BF02368294.

Quijano, S., Serrurier, A., Aubert, B., Laporte, S., Thoreux, P., Skalli, W., 2013. Threedimensional reconstruction of the lower limb from biplanar calibrated radiographs. medical engineering \& physics. Inst. Phys. Eng. Med. 35 (12), 1703-1712. http://dx.doi.org/10.1016/j.medengphy.2013.07.002.

Reed, M.P., Manary, M.A., Schneider, L.W., 1999. Methods for Measuring and Representing Automobile Occupant Posture. Society of Automotive Engineers, Warrendale, PA, Technical Paper 990959.

Reed, M.P., Park, B.K., Kim, K.H., Jones, M.L.H., 2015. Statistical prediction of body landmark locations on surface scans. In: Proceedings of 19th Triennal Congress of the IEA, Melbourne.

Sandoz, B., Laporte, S., Skalli, W., Mitton, D., 2010. Subject-specific body segment parameters' estimation using biplanar x-rays: a feasibility study. Comput. Methods Biomech. Biomed. Eng. 13 (6), 649-654. http://dx.doi.org/10.1080/ 10255841003717608.

The MakeHuman team: 〈https://makehuman.org $\rangle$.

Trochu, F., 1993. A contouring program based on dual kriging interpolation. Eng. Comput. 9, 160-177.

Yamazaki, S., Houchi, M., Mochimaru, M., 2013. Markerless landmark location on body shape scans by non rigid model fitting. In: Proceedings of 2nd International Digital Human Modeling Symposium, Ann Harbor, USA, 2013, (Online). Available: 〈http://mreed.umtri.umich.edu/DHM2013Proceedings〉.

Zhu, S., Mok, P.Y., Kwok, Y.L., 2013. An efficient human model customization method based on orthogonal-view monocular photos. Comput.-Aided Des. 45 (11), 1314-1332. http://dx.doi.org/10.1016/j.cad.2013.06.001. 